Tohoku J. exp. Med., 1984, 144, 63-67

\title{
Lack of Cross-Reactivity between Human Placental and Rat Liver Glucocerebrosidases
}

\author{
Kunihiro IIJIMA \\ Department of Neurology, Institute of Brain Diseases, \\ Tohoku University School of Medicine, Sendai 980
}

Iıנıмa, K. Lack of Cross-Reactivity between Human Placental and Rat Liver Glucocerebrosidases. Tohoku J. exp. Med., 1984, 144 (1), 63-67. —— The production of anti-human placental glucocerebrosidase antibodies in rabbits immunized with a mixture of human placental glucocerebrosidase and Freund's complete adjuvant was confirmed by the immunoprecipitation reaction, immunocompetition and Graber and Williams' immunoelectrophoresis. These immunochemical techniques also unvailed a lack of cross-reactivity between human placental and rat liver glucocerebrosidases against the rabbit antiserum. —_ human placental glucocerebrosidase ; rat liver glucocerebrosidase ; cross-reactivity

The high specificity and sensitivity of immunochemical techniques offer accurate discrimination of protein molecules from different species (Geiger et al. 1976). In the present study, we investigated the cross-reactivity between human placental and rat liver glucocerebrosidases.

\section{Materials and Methods}

Rabbits (NZB, $2 \mathrm{~kg}$, male) were immunized by a single subcutaneous injection of purified human placental glucocerebrosidase with a specific activity of $1.2 \times 10^{6}$ moles of hydrolyzed glucocerebroside per mg of protein per hr (Furbish et al. 1977). The enzyme solution, which was dissolved in phosphate buffered saline (PBS, pH 7.2), was diluted $1: 2$ with PBS and mixed with an equal volume of Freund's complete adjuvant. A booster dose of the same enzyme adjuvant mixture was injected every three weeks at a dose of $0.2 \mathrm{mg}$ enzyme protein per kg. Antisera were obtained from the rabbits 8 days after the injection of each boost. Rabbit antisera, prepared free from anti-human serum albumin antibodies (Furbish et al. 1977), were used for the following studies.

Enzyme activity of the glucocerebrosidase was assayed utilizing $\mathrm{D}-\left(1-{ }^{14} \mathrm{C}\right)$ glucocerebroside as the substrate (Brady et al. 1965). The enzyme activity is expressed as units. One unit of enzymatic activity was defined as the amount of enzyme required to catalyze the hydrolysis of $1 \mathrm{nmol}$ of substrate per hr. Protein content was estimated by a modified Lowry's method (Bensadoun and Weinstein 1976).

The Immuno-tech Agarose Plate Kit (Calbiochem-Behring Corp. La Jolla, CA) was utilized for Graber and Williams' immunoelectrophoresis (Graber and Williams 1955). After the arcs were precipitated, the plate was stained with $0.1 \%$ Comassian brilliant blue in glacial acetic acid - ethylalcohol - water $(10: 25: 65, \mathrm{v} / \mathrm{v})$.

Rat liver glucocerebrosidase was prepared as follows: Fresh rat liver (10-12 g in

Received for publication, December 28, 1983. 


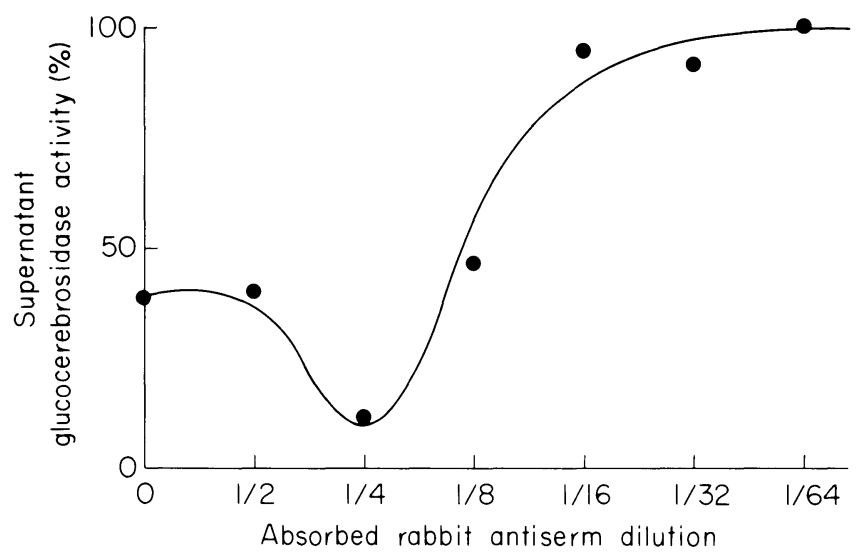

Fig. 1. Immunotitration of the absorbed rabbit anti-human placental glucocerebrosidase serum.

Supernatant human placental glucocerebrosidase activity after removing immunoprecipitates of mixtures of $40 \mu \mathrm{l}$ of $1: 100$ diluted human placental glucocerebrosidase and the same amount of a serial dilution of the absorbed rabbit antiserum, preincubated for overnight at $4^{\circ} \mathrm{C}$, was expressed as the percentage of that of the control mixture containing the same amount of the diluted enzyme and $20 \mathrm{mM}$ acetate buffer ( $\mathrm{pH} 5.0)$ instead of the rabbit antiserum.

weight) was homogenized with a glass homogenizer in $50 \mathrm{mM}$ citrate buffer ( $\mathrm{pH} 6.0$ ), containing $10 \mathrm{mg} / \mathrm{ml}$ sodium taurocholate and $2 \mathrm{mg} / \mathrm{ml}$ Triton X-100, and centrifuged at $10,000 \mathrm{rpm}$ for $1 \mathrm{hr}$ at $4^{\circ} \mathrm{C}$. The supernatant was loaded on a column packed with $25 \mathrm{ml}$ of Con A-Sepharose (Pharmacia Fine Chemicals, Uppsala). After washing with citrate buffer and then with $1 \mathrm{M} \mathrm{NaCl}$ in the same buffer, the column was eluted with $1 \mathrm{M}$ methyl-Dmannoside in citrate buffer. These eluents were dialyzed overnight against $10 \mathrm{mM}$ citrate buffer ( $\mathrm{pH}$ 6.0) and concentrated by an Amicon B 15 concentrator (Amicon Corp., Denver) if needed.

According to the results of our pilot experiment, the mixture of $40 \mu \mathrm{l}$ of $1: 100$ diluted human placental glucocerebrosidase and the same amount of a serial dilution of the absorbed rabbit anti-serum in $20 \mathrm{mM}$ acetate buffer was preincubated for overnight at $4^{\circ} \mathrm{C}$. The mixture was then centrifuged at $10,000 \mathrm{rpm}$ for $30 \mathrm{~min}$, and the enzyme activities of the supernatant were assayed. One of the rabbit antisera obtained after the 1st booster (Fig. 1) was used for the following experiments.

The cross-reactivity between the human placental glucocerebrosidase and the rat liver extracts against the absorbed rabbit antiserum was studied by the following method. We first prepared a series of increasing concentrations $(0 \sim 30 \mu \mathrm{l})$ of rat liver extract, which had been concentrated 25 times with Amicon B15; their enzymatic activities were comparable to that of diluted human placental glucocerebrosidase $(1: 100, \mathrm{v} / \mathrm{v})$. Mixtures containing $40 \mu l$ of $1: 4(\mathrm{v} / \mathrm{v})$ diluted absorbed rabbit antiserum and these rat liver extracts were preincubated for $10 \mathrm{~min}$ at room temperature prior to the start of the reaction with $40 \mu l$ of $1: 100$ diluted human placental glucocerebrosidase. The final volume of the incubation media was adjusted to $112 \mu \mathrm{l}$ with $20 \mathrm{mM}$ acetate buffer ( $\mathrm{pH}$ 6.0). After overnight incubation at $4^{\circ} \mathrm{C}$ the immunoprecipitates were removed, and the activities of the soluble enzyme were assayed (Fig. 2A). 


\section{Results And Discussion}

In the absence of the rat liver extract, the activity of the human placental glucocerebrosidase was less than $30 \%$ of that of the control mixture containing the same diluted enzyme. With increasing amounts of the rat liver extract, the curve of the enzymatic activities (Fig. 2A) became almost identical to that of the series of rabbit antiserum and rat liver extracts without human placental glucocerebrosidase (Fig. 2B). These activities were significantly lower than the activity of the series of rat liver extract and human placental glucocerebrosidase without antiserum (Fig. 2C).

The results of Graber and Williams' immunoelectrophoresis are shown in Fig. 3. A single precipitation arc was obtained between human placental glucocerebrosidase and rabbit antiserum. If the rat liver extract cross-reacts with human placental glucocerebrosidase against the rabbit antiserum, the amounts of soluble activities should approach the amounts expected in the absence of rabbit antiserum due to immunocompetition (Meisler and Ratazzi 1974).

The results from the present experiments demonstrate the absence of crossreactivity between human placental and rat liver glucocerebrosidases against rabbit anti-human placental glucocerebrosidase antibodies. Geiger et al. (1976) in the studies on hexosaminidase A attempted to quantify antigenic similarities in

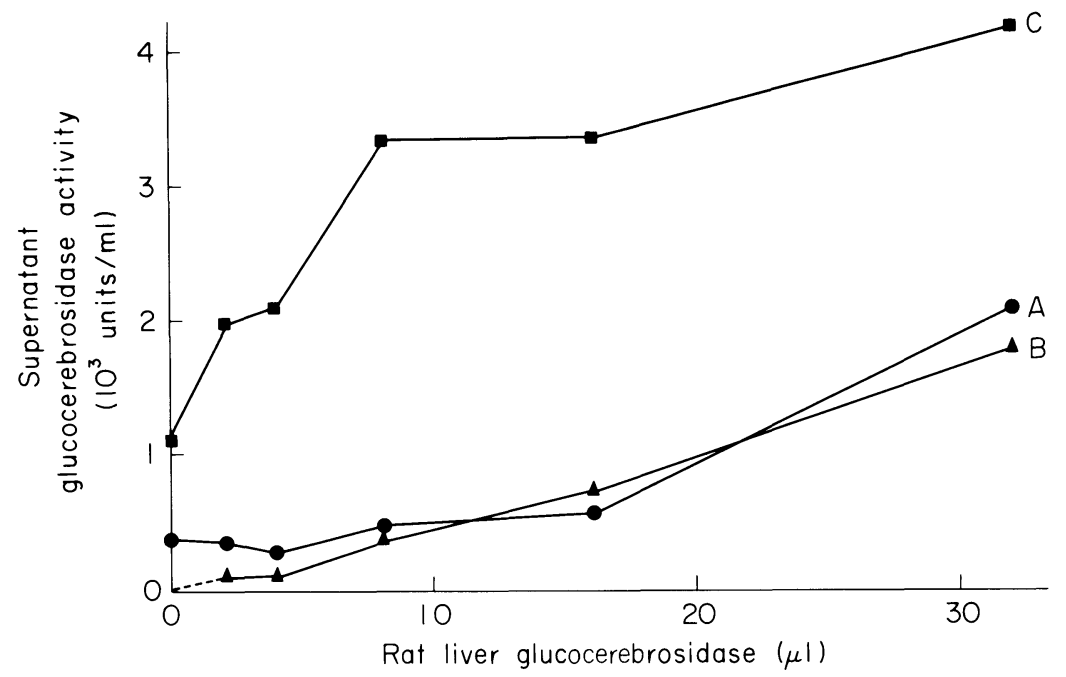

Fig. 2. Immunocompetition between human placental and rat liver glucocerebrosidase.

Mixtures of indicated aliquots of rat liver glucocerebrosidase with the absorbed rabbit antiserum (curve B), with human placental glucocerebrosidase (curve $\mathrm{C}$ ) and with both of them (curve A), adjusted to a final volume with $10 \mathrm{mM}$ citrate buffer $(\mathrm{pH} 6.0)$, were preincubated for overnight at $4^{\circ} \mathrm{C}$. After removing immunoprecipitations, the supernatant enzyme activities were assayed. 


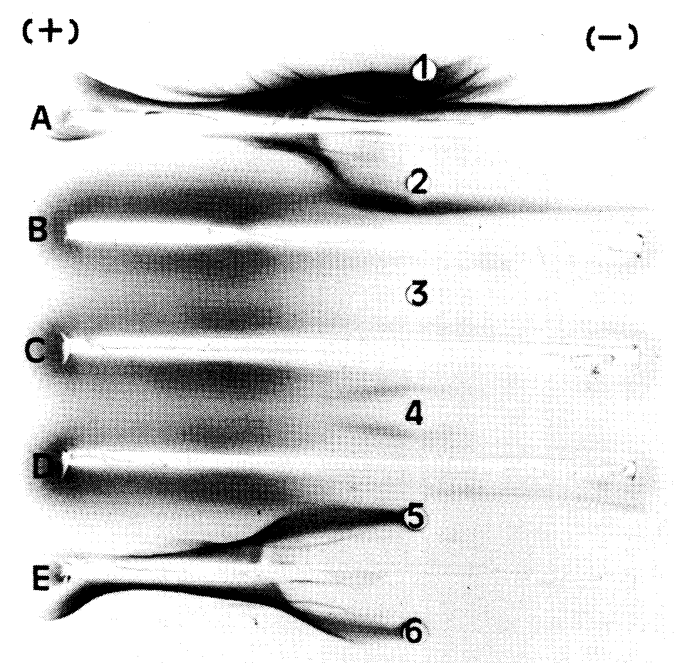

Fig. 3. Graber and Williams' immunoelectrophoresis.

The antigen wells were filled with normal human serum (1), undiluted human placental glucocerebrosidase (2), $5 \times$ concentrated rat liver extract (3), $1: 5$ diluted human placental glucocerebrosidase (4) and human serum albumin $(5,6)$. Antibody wells contained rabbit anti-normal human serum ( $\mathrm{A}$ and $\mathrm{E}$ ) and absorbed rabbit anti-human placental glucocerebrosidase (B, C, D).

accordance with evolutionary and phylogenetic relationship among the species, and they found negligible cross-reactivity between human and rat, as confirmed in the present study. Thus, there appears to be no common antigenic determinants of human placental glucocerebrosidase against the rabbit antiserum in the rat.

\section{Acknowledgments}

This study was done in the Laboratory of Developmental and Metabolic Branch, NINCDS, NIH, Bethesda, Maryland, USA.

I am grateful to Dr. Roscoe O. Brady and Dr. John A. Barranger for valuable discussion and advice.

\section{References}

1) Bensadoun, A. \& Weinstein, D. (1976) Assay of proteins in the presence of interfering materials. Analyt. Biochem., 70, 241-450.

2) Brady, R.O., Kanfer, J.N. \& Shapiro, D. (1965) Metabolism of glucocerebrosidases. Biochem. biophys. Res. Commun., 18, 221-225.

3) Britton, D.E., Leinikki, P.O., Barranger, J.A. \& Brady, R.O. (1978) Gaucher's disease : lack of antibody response to intravenous glucocerebrosidase. Life Sci., 23, 2517-2519.

4) Furbish, F.S., Blair, H.E., Shiloach, J., Pentchev, P.G. \& Brady, R.O. (1977) Enzyme replacement therapy in Gaucher's disease: large-scale purification of 
glucocerebrosidase suitable for human administration. Proc. nat. Acad. Sci. USA, 74, 3560-3563.

5) Geiger, B., Ben-Yoseph, Y. \& Aron, R. (1976) Immunological relationships among hexosaminidases of different species. Immunochemistry, 13, 485-490.

6) Graber, P. \& Williams, C.A. (1955) Methode immuno-electrophoretique d'analyse de milianges de substances antigeniques. Biophys. Acta, 17, 67-74.

7) Meisler, M. \& Ratazzi, M.C. (1974) Immunological studies of $\beta$-galactosidase in normal human liver and in $\mathrm{GM}_{1}$ gangliosidosis. Amer. J. hum. Genet., 26, 638-691. 